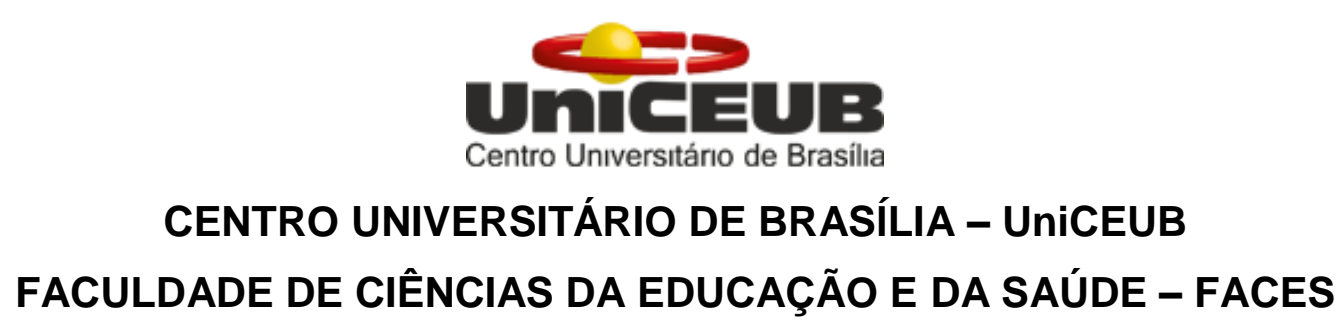

PROGRAMA DE INICIAÇÃO CIENTÍFICA

IGOR RIBEIRO DO NASCIMENTO

THAÍS LIMA DE SENA

BIOFILMES BACTERIANOS: COLONIZAÇÃO E IDENTIFICAÇÃO DE MICRO-ORGANISMOS CAUSADORES DE INFECÇÃO EM CATETER VENOSO CENTRAL

BRASÍLIA-DF

2017 


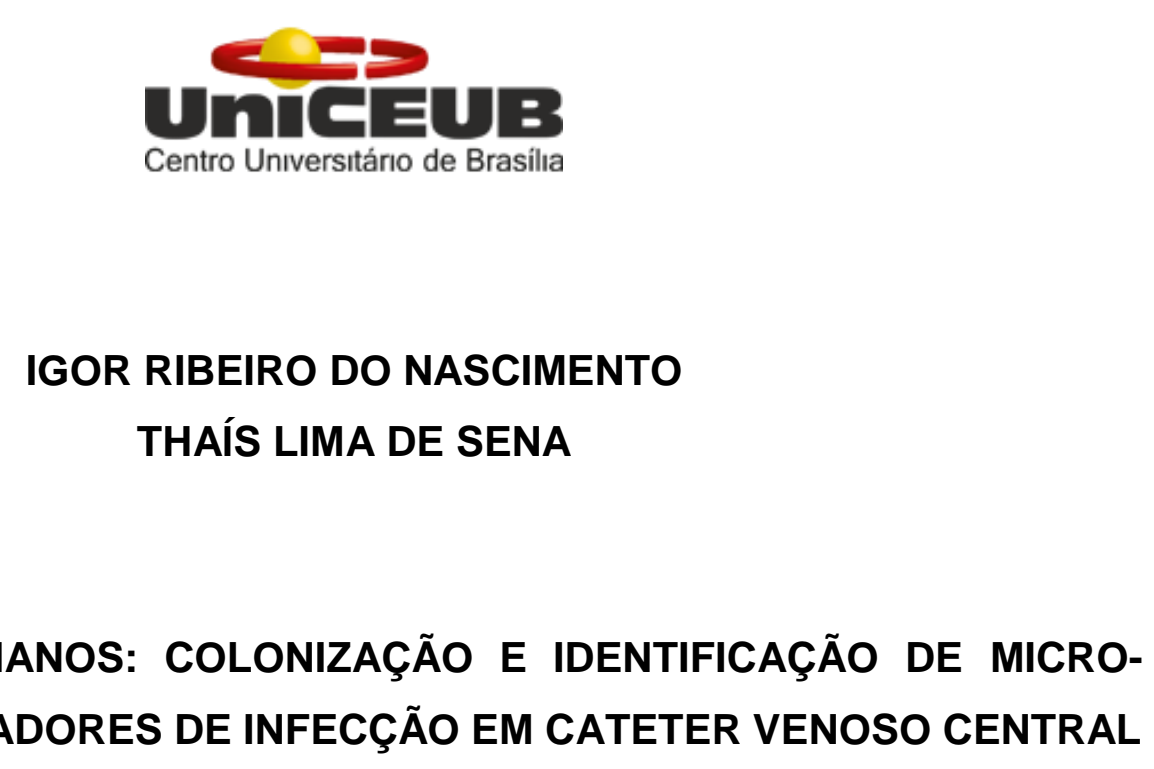

BIOFILMES BACTERIANOS: COLONIZAÇÃO E IDENTIFICAÇÃO DE MICROORGANISMOS CAUSADORES DE INFECÇÃO EM CATETER VENOSO CENTRAL

Relatório final de pesquisa de Iniciação Científica apresentado à Assessoria de Pós-Graduação e Pesquisa pela Faculdade de Ciências da Educação e da Saúde - FACES.

Orientação: Fabíola Fernandes Castro

BRASÍLIA-DF 2017 


\title{
BIOFILMES BACTERIANOS: COLONIZAÇÃO E IDENTIFICAÇÃO DE MICRO- ORGANISMOS CAUSADORES DE INFECÇÃO EM CATETER VENOSO CENTRAL
}

\author{
Igor Ribeiro Nascimento - UniCEUB, PIC Institucional, aluno bolsista \\ igorribeiru123@hotmail.com
}

Thaís Lima de Sena - UniCEUB, PIC institucional, aluna voluntária

thaaais.sena@gmail.com

Fabíola Fernandes dos Santos Castro - UniCEUB, professora orientadora

fabiolafcastro@gmail.com

Polyana Pereira Correia de Souza - Instituto de Cardiologia do DF, colaboradora

Fernanda Nomiyama Figueiredo- Universidade Católica de Brasilia-UCB, colaboradora

Entende-se por biofilme bacteriano, uma comunidade complexa composta por uma única, ou diversas espécies de micro-organismos, estes, se encontram aderidos a uma superfície e revestidos por uma camada heterogênea de matriz extracelular que é capaz de diferenciar o ambiente onde estão presentes. A grande capacidade de adaptação em diversos tipos de substratos, ambientes, e a sua diversidade metabólica, tornam estes micro-organismos distintos dos isolados em outras infecções. A presença de biofilmes desempenha um papel fundamental no desenvolvimento de doenças infecciosas, pois podem ser formadas em todas as superfícies do corpo, persistir mesmo após tratamento com altas doses de agentes antimicrobianos, e ainda, tornar-se resistente a eles. Em média, 70\% de todas as infecções relacionadas a assistência estão vinculadas à presença de biofilmes em dispositivos médicos. A utilização destes dispositivos, é importante para o tratamento de vários pacientes e todo indivíduo que faz seu uso, está susceptível a infecções no cateter. A produção de biofilme em cateter venoso central vem se destacando como um problema de saúde pública, pois contribuem significativamente com o aumento da morbimortalidade destes pacientes, aumentando o tempo de internação, custos hospitalares e a diminuição da qualidade de vida. A identificação destes patógenos é realizada através da metodologia de Maki, que possui um grande número de resultados falsonegativos devido a limitações da técnica e a presença de biofilmes, em contra partida, o método de Sonicação permite a desestruturação física do biofilme, através de um banho ultrassônico, permitindo que os micro-organismos presentes no mesmo possam ser identificados. O presente estudo comparou as duas metodologias em 50 amostras de cateteres venoso central oriundos de pacientes submetidos a retirada do cateter venoso central devido a suspeita de infecção, em hospitais de grande porte na cidade de Brasília-DF, onde mais de $30 \%$ das amostras apresentaram resultado positivo no método de Sonicação ao se comparar com o método de Maki, dentre as quais foram identificados Sphingomonas paucimobilis, Sthaphylococcus aureus e Ralstonia pickettii.

Palavras-Chave: Biofilme. Maki. Sonicação. Cateter. Infecção 


\section{SUMÁRIO}

1. INTRODUÇÃO - 5

2. OBJETIVO-- 6

3.REFERENCIAL TEÓRICO--

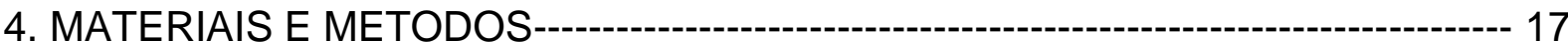

5. RESULTADOS--- 19

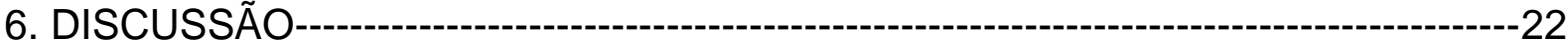

7. CONCLUSÃO--

REFERÊNCIAS--.-- 30 


\section{INTRODUÇÃO}

As infecções hospitalares constituem um sério problema de saúde no mundo. São consideradas uma das primeiras e principais causas de morbidade, mortalidade e custos, uma vez que aumentam sensivelmente a frequência de complicações e sequelas; exigem tratamentos invasivos; prolongam a permanência hospitalar dos pacientes; reduzem a disponibilidades de leitos para as pessoas; aumentam os custos do atendimento; induzem a utilização de doses duas vezes maiores de antimicrobianos que quase sempre são mais tóxicos e caros; podem levar à resistência bacteriana, cujo crescimento têm sido expressivo desde a última década e sobretudo sua evolução pode ser fatal. Contudo, ainda são poucos os relatos sobre o perfil e a amplitude dessa resistência no ambiente hospitalar em todo o Brasil (WEBER et al., 2009).

Os cateteres venosos centrais (CVC), são os dispositivos invasivos mais utilizados no mundo e de essencial importância para o tratamento de pacientes hospitalizados com internações prolongadas e realização de procedimentos hospitalares, tais como administração de soluções, medicamentos, sangue e derivados, cateterismo cardíaco, exames radiológicos com utilização de contraste, monitorização de status hemodinâmico e realização de hemodiálise, entre outros. O uso prolongado desses cateteres representa uma fonte potente de complicações infecciosas, tanto por infecção local evidenciados pela colonização do cateter, quanto por episódios de infecção sistêmica que ocorrem como resultado direto da presença dele (DIENER; COUTINHO; ZOCCOLI, 2006). O uso de CVC está associado a um risco de colonização e logo após infecção (MERMEL et al., 2009).

A infecção relacionada ao cateter ocorre sempre devido à formação do biofilme. A maioria dos microrganismos envolvidos na colonização do cateter são virulentos na forma planctônica, mas podem causar infecção persistente, quando estão agrupados formando o biofilme (RIMONDINI et al., 2005). 
Biofilme refere-se a uma comunidade composta por várias espécies de microorganismos, estes crescem aderidos a uma superfície, seja biótica ou abiótica como: cateteres, sondas, próteses e outros dispositivos biomédicos utilizados na conduta clínica hospitalar e, são revestidos por uma camada heterogênea complexa de matriz extracelular contendo polissacarídeos, proteínas e ácidos nucleicos estes, produzidos pelos próprios micro-organismos (MENOITA et al., 2012; HENRIQUES , et al., 2013; SHIESARI JUNIOR, et al., 2015).

Os micro-organismos associados a infecções por biofilmes se comportam fisiologicamente diferente no que se refere à sua taxa de crescimento, capacidade de resistência à antimicrobianos e aumento da resistência à resposta imune do hospedeiro, devido a matriz que envolve os micro-organismos, sendo de difícil acesso aos agentes antimicrobianos (PINHEIRO, 2006).

É valido ressaltar que os biofilmes desempenham papel fundamental no desenvolvimento de doenças infecciosas, e podem ser formados em qualquer superfície do corpo, podendo persistir mesmo após tratamento com altas doses de agentes antimicrobianos. Estudos demostram que biofilmes podem ser iniciados após três dias da inserção de um cateter e que predominam na superfície externa do dispositivo após 10 dias, com aumento do tempo de permanência do mesmo por mais de 30 dias, a formação do biofilme é predominante no lúmen do cateter (DONLAN, COSTERTON, 2002; SALDANHA, 2013).

O comportamento bacteriano relacionado ao biofilme se dá a uma mudança na fisiologia bacteriana, passando da forma planctónica onde estes micro-organismos de encontram em vida livre e é a partir desta forma que ocorre a rápida propagação e disseminação das bactérias para outros ambientes. $E$ as formas sésseis, que estão presentes no biofilme, onde as bactérias estão aderidas a uma superfície sólida, estima-se que $90 \%$ dos micro-organismos existam sob a forma de biofilmes, e estes, podem ser encontrados em quase todos os tipos de superfície (CAUMO et al., 2010; MENOITA et al., 2012; HENRIQUES et al., 2013).

\section{OBJETIVO}


O trabalho teve como objetivo principal comparar a eficácia dos métodos de culturas semi-quantitativo (Método de Maki), utilizados rotineiramente em laboratório hospitalar do Instituto de Cardiologia do Distrito Federal, localizado na cidade de Brasília com o método quantitativo (Sonicação) em relação ao isolamento de microorganismos encontrados em cateter venoso central utilizados por pacientes de unidade de terapia intensiva (UTI).

\section{REFERENCIAL TEÓRICO}

\subsection{Biofilmes bacterianos}

A descrição dos biofilmes bacterianos vem sendo discutida em muitos sistemas desde Antonie van Leeuwenhoek, em 1675, que foi através da análise de animais pequenos nos dentes, mas a teoria geral da existência de biofilmes só foi publicada em 1978, através de um estudo realizado por Costerton, Geesey e Cheng. A partir dessa publicação, foi observado que várias bactérias não se desenvolvem igualmente quando comparadas como células individuais, mas sim em comunidades estruturadas, como exemplo possuíam organismos pseudomulticelulares, ou melhor, biofilmes, onde estariam presentes em todos os ecossistemas naturais e patogênicos (COSTERTON et al., 1981; LÓPEZ; VLAMAKIS; KOLTER, 2010).

A capacidade de adaptação em ambientes diferentes e variabilidade metabólica fazem parte das características fundamentais de micro-organismos presentes em biofilmes. Pode-se definir que as bactérias possuem dois estados básicos de vida: como células planctônicas, que podem ser caracterizadas como células de vida livre, e tem metabolismo mais ativo e as células sésseis, que são as células que compõe os biofilmes, que possuem um metabolismo mais compensado. As células planctônicas são essenciais para garantir rápida proliferação e pode resultar na disseminação dos micro-organismos para outros locais, por outro lado as células sésseis tem a característica de cronicidade (CONSTERTON et al., 1981).

O termo biofilme pode ser definido por um ecossistema ou comunidade microbiológica complexa, que tem a sua caracterização por células irreversíveis que possui adesão a um substrato ou podendo estar aderida entre si e colocadas em uma 
matriz formada de polissacarídeos extracelular de produção própria. Estes ainda, podem interagir de modo isolado ou combinado, devido a esta matriz. As bactérias presentes em biofilmes encontram-se protegidas do sistema imunológico e da exposição à antimicrobianos, potencializando a dificuldade de seu tratamento (CAIXETA, 2008; SALDANHA, 2013).

Sua formação tem início com adesão primaria destas bactérias em sua forma planctônica a uma determinada superfície, este processo é considerado 8 complexo, pois ocorre através da interações físico-químicas não especificas entre a bactéria e a superfície abiótica (inanimada, plástico e metais por exemplo), esta interação ocorre aleatoriamente, através de força gravitacional, movimento browniano ou de forma ordenada, através de mecanismos de cada patógeno como quimiotaxia e motilidade através de flagelos e pili, este estado é reversível, assim, relatado por interações físico-químicas não especificas de longo alcance entre os mesmos, incluindo forças hidrodinâmicas, hidrofóbicas, eletroestáticas, força de van Walls e força de atração e repulsão entre esta interação, que será o fator primordial para determinação desta fase de adesão, estes mecanismo ainda estão em fases de estudo e não totalmente elucidados ( MORAES, et al., 2013; TRENTI et al, 2013).

Enquanto a adesão em superfícies bióticas (células e tecidos animais e vegetais por exemplo), e observada através de interações moleculares mediadas por ligações especificas (ligante-receptor). Depois de aderidos, ocorre a proliferação destes microorganismos levando a um acúmulo dos mesmos, são produzidas substâncias que tem a função de atrair outros micro-organismos, e fazer com que as células bacterianas produzam uma matriz de exopolissacarídeo (EPS), que se comporta como uma membrana protetora que recobre totalmente a comunidade bacteriana, tornando o ambiente interno a ele diferenciado, assim, podendo ocorrer alterações de $\mathrm{pH}$, temperatura, umidade, produção de toxinas, expressão dos fatores de virulência e até mesmo troca plasmidial (DONLAN, et al, 2001; CAIXETA, 2008; FLACH, 2005).

As substâncias produzidas, fazem com que a densidade bacteriana aumente, através da presença de moléculas autoindutoras que ao se acumular induzem a transcrição de genes específicos, regulando várias funções bacterianas, como motilidade, virulência e a capacidade de produção de EPS. Este processo de 
comunicação pode ser encontrado em diversos microorganismos, muitas vezes associado a bactérias patogênicas e é referido como Quorum sensing (sistema de comunicação intra e interespécies de microrganismos) (RUTHERFORD; BASSLER, 2012, TRENTI et al., 2013).

A segunda etapa é a adesão secundária ou adesão irreversível. As bactérias que se aderem à superfície (colonizadores primários) passam a se multiplicar, formando macro-côlonias, estas, começam a sintetizar EPS e estabelecem o processo de adesão. Durante essa fase, os patógenos são capazes de se ligar a células da mesma ou de diferentes espécies (colonizadores 9 secundários), que podem utilizar o EPS como substrato, formando agregados com os micro-organismos já aderidos a superfície (STOODLEY et al., 2002, MENOITA, 2012).

Após estruturado a formação inicial do biofilme, ocorre o processo de troca de substâncias entre o meio interno e o externo. Este transporte é possível através do gradiente de concentração, e pelos sinalizadores produzidos pelos micro-organismos, fazendo com que o EPS seja mais seletivo, e as bactérias mais próximas a extremidades do mesmo tenham o metabolismo mais ativo do que as que foram aderidas inicialmente (MENOITA, 2012).

$\mathrm{Na}$ próxima etapa, ocorre o processo de dispersão/deslocamento ou desprendimento de porções de biofilme, conhecido como erosão, ou, "sloughing off", em determinadas situações, o ambiente pode não se encontrar mais favorável, por alterações ambientais, ou devido a programação celular exercidas pelas próprias bactérias. Podem ocorrer no intuito de "crescimento" da área acometida pelo biofilme, incidindo o desprendimento de células mais externas a matriz, ou pelo processo de abrasão, devido a constantes colisões que ocorrem entre a superfície em que o biofilme está aderido e o meio em que se encontra (XAVIER, 2002; MENOITA, 2012; TRENTIN, et al., 2013). A figura 1 retrata a formação de um biofilme e as fases associadas a ele. 


\section{Figura 1- Formação do biofilme bacteriano e suas fases de formação}

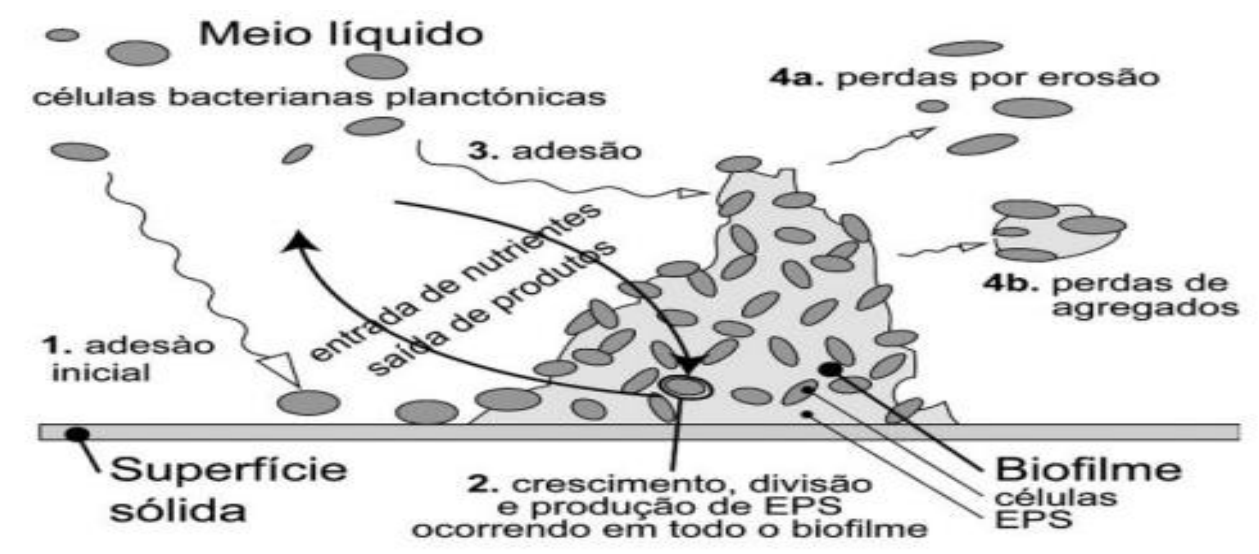

Fonte: XAVIER, et al., 2002

Existem infecções que são proporcionadas por alguns patógenos que se tornaram multirresistentes a antimicrobianos, sendo um dos grandes desafios presentes na saúde pública atualmente, impactando no aumento de morbidade e mortalidade e consequentemente no aumento do tempo de internação e nos gastos do sistema de saúde (NEIDELL et al., 2012).

O órgão norte-americano "National Institute of Health" $(\mathrm{NIH})$ afirma que os biofilmes tem relação em torno de $80 \%$ de todas as infecções médicas no mundo $(\mathrm{NIH}$, 2002), onde as principais são: endocardites, otites, prostatites, periodontites, conjuntivites, vaginites, infecções que tem relação com a fibrose cística e colonizadores de implantes biomédicos, como: cateteres venosos, arteriais e urinários, dispositivos intrauterinos, lentes de contato e próteses, estes últimos geralmente sendo as infecções mais importantes (DONLAN; COSTERTON, 2002; HOIBY et al., 2011).

Quando estas células têm resistência aos antimicrobianos, torna-se prejudicial para o paciente, ao utilizar um antimicrobiano com o intuito de se acabar com a infeção, obtém-se como resultado uma reinfecção. Pois nem todos os microorganismos sofreram com a ação do antimicrobiano. Patógenos que tem esta característica são chamados de dormentes ou persistentes. Possuem baixa taxa 
metabólica e são comuns de serem encontrados na estrutura dos biofilmes, onde tem pouca oferta de oxigênio. $O$ baixo metabolismo dessas células persistentes faz com que estas venham a se tornar mais seletivas, tornando-as resistentes aos antimicrobianos, é conhecido que o antimicrobiano normalmente tem o seu mecanismo de ação no período de crescimento da bactéria, como na síntese proteica, síntese de ácidos nucléicos e de parede celular. Portanto o antimicrobiano vai ser eficaz na maior parte da população de bactérias em biofilme, exceto nas persistentes, o que pode proporcionar reinfecção, quando a terapia não propicia outro subterfugio na eliminação destes patógenos (STEWART, 2002; LEWIS, 2012).

Desta forma é possível de analisar que a presença dos biofilmes é multifatorial e essa resistência foi desenvolvida como uma resposta de estresse do micro-organismo ao meio em que se encontra, devido que a vida em biofilmes permite que as células produzam respostas diferenciadas ás alterações ambientais (MAH, 2012, TRENTI et al., 2013).

Nos últimos anos, o cateter venoso central está sendo indicado como uma medida emergencial e paliativa no intuito de salvar a vida de muitos indivíduos, seu uso tem especificidade para ser utilizados em situações críticas. Esses dispositivos podem chegar a serem utilizados por um período de tempo prolongado (NEVES JUNIOR et al., 2010).

\subsection{Infecção relacionada ao catéter}

O cateter do tipo Hickman é um dispositivo essencial na área da saúde, desde quando se iniciou a sua utilização até os dias atuais, sendo uns dos cateteres mais utilizados na pratica médica, geralmente em pacientes que estão nos hospitais e internados. Sua indicação é para administração de soluções intravenosas, medicamentos, hemotransfusões, nutrição parenteral, uso de contraste e monitorização hemodinâmica (ALBUQUERQUE, 2005; SILVEIRA, 2005; COUTO; PEDROSA; NOGUEIRA, 2009; BRASIL, 2010). 
A Utilização desses dispositivos é importante para o tratamento de vários pacientes, entretanto, a literatura afirma que qualquer indivíduo que necessite do uso do dispositivo pode estar susceptível a desencadear infecções locais ou sistêmicas podendo induzir riscos significativos ao indivíduo e levar a morte. Quando a infecção tem relação com o cateter, ou seja, quando acontece a colonização de seu lúmen, parte externa ou ponta são denominadas infecções locais ou de corrente sanguínea já quando a infecção atinge a pele, tecidos adjacentes ou no ponto de inserção do dispositivo, são denominadas infecções locais quando ocorrem seguidas de bacteremia e/ou sepse, sendo denominadas nestes casos de sistêmicas (OLIVEIRA, 2009; CDC 2011).

O cateter de plástico foi introduzido em 1945, facilitando a terapia intravenosa prolongada. Notificações de casos de complicações devido à terapia de infusão logo apareceram. Na primeira década os cateteres de plástico foram inseridos na veia femoral. Outras veias periféricas também foram usadas (MAKI et al., 1973).

Neuhof e Seley (1947) notificaram seis casos de sepse, as quais foram atribuídas à inserção do cateter. Vários investigadores especularam que o fluído da infusão era a fonte da sepse.

Moncrief (1958) notificou quatro casos de tromboflebite com septicemia fatal e encontrou uma associação entre a incidência da complicação e o tempo de permanência do cateter. Notificações subsequentes enfatizaram o perigo da trombose induzida pelo cateter e sepse, principalmente depois da inserção do cateter e esgotada a necessidade de usar meticulosos métodos de antissepsia no momento da cateterização (INDAR, 1959).

Antes de 1950 alertas em duas revisões de literatura sobre a septicemia estafilocócica foram dados ao problema da infecção associada, na qual notara-se que pelo menos metade dos pacientes que desenvolveram septicemia por Staphylococcus aureus tinha infecção no local de inserção do cateter (HASSAL, 1959). 
Um levantamento mostrou que o Control of Infections in Hospitals (1962) nunca mencionou a terapia intravenosa como uma fonte de infecção e o primeiro estudo prospectivo do problema nunca apareceu até 1963 (DRUSKIN, SIEGEL, 1963).

Maki et al. (1973) notificaram que a infusão intravenosa tornou-se indispensável na terapia moderna, mas a infecção, especialmente a septicemia associada à infusão tornou-se um risco ameaçador à vida. Na década de setenta o Centers for Disease of Control and Prevention (CDC) notificou o problema da infecção relacionada à infusão.

A contaminação do sistema intravenoso pode ocorrer em qualquer ponto, desde o momento do processamento até o término da infusão no hospital. Ocorrida uma contaminação, a cânula intravenosa e o trombo aderente formado podem servir como um foco intravascular para a proliferação e disseminação de microrganismos. Alguns patógenos crescem abundantemente em fluídos de infusão em temperatura ambiente, excedendo concentrações de até 105 organismos $/ \mathrm{ml}$ em 24 horas. Os autores sugeriram o reconhecimento de que a contaminação do fluído de infusão é uma potencial causa de septicemia.

Raad e Bodey (1992) observaram que a infecção relacionada ao cateter pode ser dividida em duas principais categorias: infecções locais e septicemias sistêmicas relacionadas ao cateter. Collignon (1994) relatou que as infecções associadas ao cateter podem ser locais e sistêmicas. O fenômeno local inclui simples colonização ou infecção verdadeira que pode envolver o sítio de saída ou o túnel. A infecção sistêmica envolve infecção da corrente sanguínea. Um exame clínico bem feito não deveria negligenciar no diagnóstico, a infecção relacionada ao cateter intravascular. $\mathrm{Na}$ maioria dos casos de bacteriemia associada ao cateter (em contraste com a bacteriemia associada aos cateteres de veia periférica) não existem evidências de sepse no local de inserção.

Bullard e Dunn (1996) observaram que a infecção é a complicação mais comum associada ao uso de cateteres venosos centrais com a subsequente bacteriemia, ocorrendo entre 3 a $5 \%$ com alta morbidade e consequências letais. Atela et al. (1997) informaram que a infecção associada aos cateteres venosos centrais é uma complicação potencialmente séria e comum. A infecção local é frequentemente assintomática mesmo na presença de bacteriemia relacionada ao cateter e o sinal 
mais frequente é uma febre de origem desconhecida. No entanto, a febre é frequentemente relatada em pacientes hospitalizados. Se a febre é devido ao cateter, outras fontes ou mesmo casos não infecciosos são difíceis para verificar. A situação é, portanto, complicada pelo fato de que múltiplos cateteres são inseridos em muitos pacientes, particularmente aqueles em unidades de terapia intensiva.

Crump e Collignon (2000) relataram que infecções muito sérias associadas ao cateter intravascular são comuns. Os dados disponíveis sugerem que existem mais de 500.000 casos de infecções da corrente sanguínea associada ao cateter, ocorrendo na parte oeste da Europa e nos Estados Unidos. Estas infecções devem estar associadas com 100.000 mortes. A patofisiologia desta condição tão comum ainda não está completamente elucidada. Com cateteres que estão inseridos por períodos curtos (dias), predomina a migração microbiana pela superfície externa do cateter para a ponta do cateter intravascular. Para cateteres que estão inseridos por longos períodos, a migração ocorre pelo lúmen interno. Após permanecer por mais de 8 dias, aproximadamente todos cateteres de veia central terão microrganismos embutidos em biofilme dentro do lúmen do cateter. Em alguns cateteres, os microrganismos aumentam em número suficiente causando uma sepse sistêmica.

A ocorrência e a taxa de proliferação dependem da virulência microbiana, fatores do hospedeiro e características do cateter. Maki e Crinch (2003) mostraram que os cateteres mais associados à infecção são os cateteres não tunelizados de único ou múltiplo lúmem, de curta permanência inseridos percutaneamente nas veias subclávia ou jugular interna.

\subsection{Fatores relevantes que potencialmente levam a infecção no cateter venoso central}

A pele é um fator de risco muito relevante para infecção em pacientes com uso de cateter venoso central. Em média são disponibilizados em torno de 150 milhões de dispositivos intravasculares por ano nos hospitais e clínicas dos Estados Unidos, entre estes, mais de cinco milhões são cateter venoso central. Devido aos avanços 
tecnológicos estes cateteres são capazes de favorecer a 13 manutenção de acesso vascular por tempo prolongado tornando maior sua frequência de uso. $E$ tem como consequência o aumento de infecções (MESIANO, HAMANN, 2007).

O uso de cateter é apontado como um dos fatores principais para infecção na corrente sanguínea, na figura 2 abaixo, observamos um modelo de cateter venoso central do tipo Hickman, que é muito difundido na pratica clinica devido a diversidade de funções, como administração de soluções e transfusões (ALBUQUERQUE, 2015).

Pacientes em uso de cateter que apresentem pelo menos um dos seguintes sinais ou sintomas devem ser investigados: febre $\left(>38^{\circ} \mathrm{C}\right)$, tremores, oligúria (volume urinário $\left.38^{\circ} \mathrm{C}\right)$, hipotermia $\left(<36^{\circ} \mathrm{C}\right)$, bradicardia ou taquicardia, e, se sintomas não estão relacionados com infecção em outro sítio anatômico em ambos os casos. Nesses casos, o paciente deve ser investigado, realizando hemocultura e cultura do próprio cateter (NEVES JUNIOR, 2010).

Figura 2- Modelo de Cateter Venoso Central- tipo Hickman

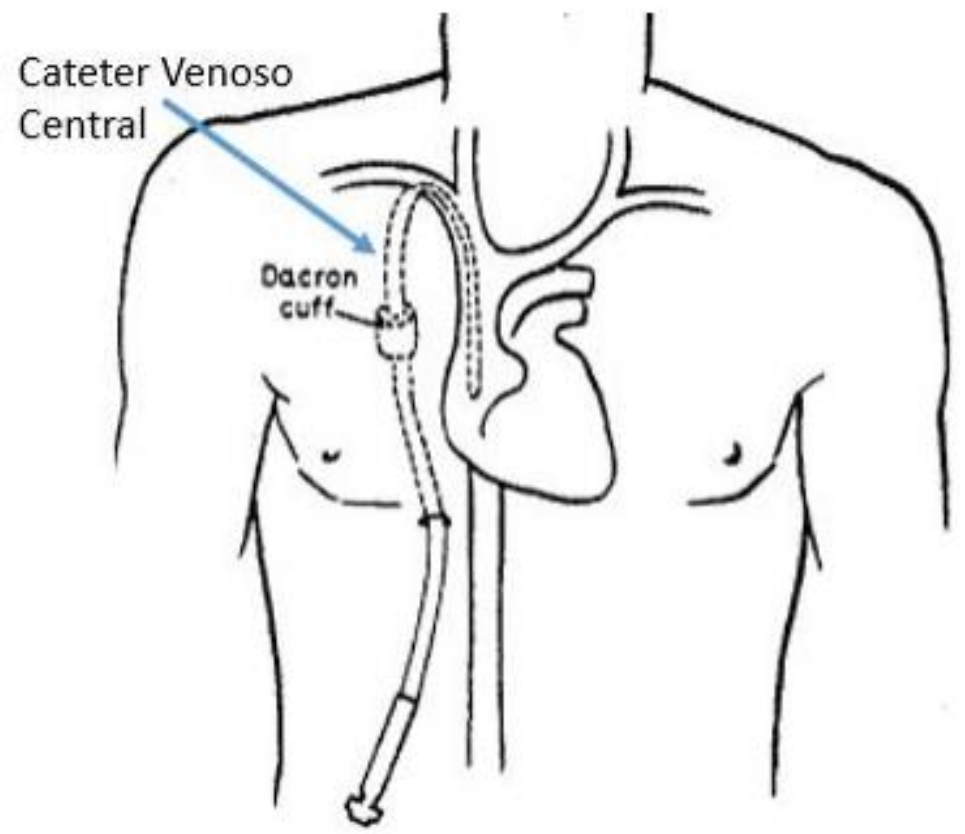

Fonte: adaptado de MARTINS e LIMA, 1998 


\subsection{Infecções primarias de corrente sanguínea em CVC no Brasil de 2011 a 2014}

No ano de 2011, foram notificadas 33.728 infecções primárias da corrente sanguínea (IPCS), dentre as quais 21.285 tiveram confirmação laboratorial, 957 hospitais notificaram IPCS em UTI adulto, totalizando 12.934 notificações com confirmação laboratorial, sendo este, o maior índice de confirmação microbiológica (72\%), com densidade de incidência clínica de 2,4 casos em 1000 cateter-dia, e densidade de incidência laboratorial de 6,2 em 1000 cateter-dia. Para a UTI pediátrica, os dados apresentados relataram 363 hospitais notificaram casos de IPCS, com o total de 3.430 notificações, dentre as quais $63 \%$ foram confirmadas laboratorialmente, observa-se que a densidade de incidência clinica é de 5 a cada 1000 cateteres dia e a densidade de incidência laboratorial é de 8,9 a cada 1000 cateteres dia.

Na UTI neonatal, foram contabilizadas 12.337 IPCS, sendo destas 6.157 tiveram confirmação laboratorial, dentre as quais se observa maior densidade de incidência laboratorial $(12,5)$ nos recém-nascidos maiores que $2.500 \mathrm{~g}$.

\section{MATERIAIS E MÉTODOS}

\subsection{Participantes da pesquisa}

As amostras utilizadas no presente projeto serão obtidas em parceria com Instituto de Cardiologia de Brasília- INCOR, de pacientes que apresentam histórico clínico de suspeita de infecção de cateter venoso central, onde o médico assistente solicitou analise microbiológica do mesmo, serão utilizadas amostras de pacientes que realizaram a retirada do cateter no hospital, não se tendo distinção de sexo, idade e estado de saúde. O aluno não terá nenhum contato com o paciente.

\subsection{Critérios de inclusão e exclusão}

\subsubsection{Inclusão}


Paciente em que foi solicitado retirada de Cateter venoso central pelo médico assistente e realizou procedimento no Hospitais Santa Luzia, Santa Helena, Instituto de Cardiologia -IC DF, sobre suspeita de infecção de cateter.

\subsubsection{Exclusão}

Paciente em que foi solicitada a retirada de Cateter venoso central após período de uso estipulado pelo médico assistente e que não apresentou sintomatologia especifica de suspeita de infeção.

\subsection{Obtenção das amostras de cateter venoso central e solicitação de aprovação do comitê de ética}

As amostras que foram obtidas em parceria com o laboratório de Microbiologia do Instituto de Cardiologia - IC DF e Rede D'OR São Luiz com sede em Brasília por intervenção da professora orientadora, através de autorização prestada por carta de anuência elaborada de acordo com a Resolução 466/2012- CNS/CONEP. E aprovação no comitê de ética pelo parecer CAAE: 61641416.8.0000.0023 e Número do Comprovante: 114872/2016.

\subsection{Realização do Método semi-quantitativo (MAKI)}

1- Consiste na rolagem da ponta do cateter, com auxilio de pinça estéril sobre o meio de cultura Agar sangue

2- Incubação a $37^{\circ} \mathrm{C}$

3- $\quad$ Leitura após $24 \mathrm{hr}$ após o inoculo

4- Identificação das cepas bacterianas isoladas

5- A realização do MAKI foi realizada no laboratório de microbiologia dos hospitais, somente após ser empregada essa metodologia que os cateteres foram disponibilizados para a pesquisa. 


\subsection{Realização do Método de Sonicação}

A metodologia necessita do aparelho de banho ultrassônico para ser processado, o experimento foi realizado em parceria com a Universidade Católica de Brasília- Núcleo de Pós Graduação através da colaboradora do projeto Fernanda Nomiyama Figueiredo, no laboratório de pesquisa.

A sonicação trata-se de um método físico que envolve a aplicação de ultrassom para quebrar as interações intermoleculares, rompendo assim o biofilme presentes nos cateteres e liberando os micro-organismos para o meio externo. Concite em:

1- Imersão do cateter em solução de $\mathrm{NaCl}$ a $0,9 \%$ estéril (10mL)

2- Exposição a banho ultrassônico por 10 minutos

3- Cultivo de solução em Ágar Sangue de Carneiro

4- Incubação a $37^{\circ} \mathrm{C}$

5- $\quad$ Leitura após 24 ou $48 \mathrm{~h}$

6- Identificação dos micro-organismos isolados

\subsection{Realização do teste de sensibilidade a antimicrobianos}

O teste de sensibilidade a antimicrobianos foi realizado no Instituto do Coração IC DF, pela metodologia VITEK®, onde a escolha dos antibióticos foi realizada de acordo com o documento Performance Standards for Antimicrobial Susceptibility Testing - CLSI 2017, através de cartões específicos para perfis de cepas bactérias e espécies isoladas.

\section{RESULTADOS}

Todo o experimento foi realizado no laboratório de Microbiologia do Centro Universitário de Brasília, UniCEUB. As amostras foram obtidas foram processadas na metodologia de sonicação na Universidade Católica de Brasília, onde foram 
transportadas em caixa de isopor higienizada em Falcon estéril e vedados com parafina para evitar contaminação cruzada.

A partir da metodologia de sonicação empregada, utilizou-se $10 \mu \mathrm{L}$ como inoculo, em duplicata, e ao final da incubação, usualmente 48 horas, as colônias foram identificadas pela metodologia de VITEK®, onde as positivas foram submetidas ao teste de sensibilidade a antimicrobianos, foram totalizadas 56 amostras de cateter venoso central das quais foram realizadas as duas metodologias.O quadro 1 abaixo demostra os resultados obtidos após período de incubação:

\section{Quadro 1- Resultado crescimento bacteriano}

\begin{tabular}{|l|l|l|}
\hline N DA AMOSTRA & RESULTADO MAKI & $\begin{array}{l}\text { RESULTADO } \\
\text { SONICAÇÃO }\end{array}$ \\
\hline 1 & NEGATIVO & NEGATIVO \\
\hline 2 & NEGATIVO & NEGATIVO \\
\hline 3 & NEGATIVO & NEGATIVO \\
\hline 4 & NEGATIVO & NEGATIVO \\
\hline 5 & NEGATIVO & POSITIVO \\
\hline 6 & NEGATIVO & POSITIVO \\
\hline 7 & NEGATIVO & NEGATIVO \\
\hline 8 & NEGATIVO & NEGATIVO \\
\hline 9 & NEGATIVO & NEGATIVO \\
\hline 10 & NEGATIVO & NEGATIVO \\
\hline 11 & NEGATIVO & NEGATIVO \\
\hline 12 & POSITIVO & POSITIVO \\
\hline 13 & POSITIVO & POSITIVO \\
\hline 14 & NEGATIVO & NEGATIVO \\
\hline 15 & NEGATIVO & NEGATIVO \\
\hline 16 & NEGATIVO & POSITIVO \\
\hline 17 & NEGATIVO & POSITIVO \\
\hline 18 & NEGATIVO & POSITIVO \\
\hline 19 & NEGATIVO & NEGATIVO \\
\hline 20 & NEGATIVO & POSITIVO \\
\hline
\end{tabular}




\begin{tabular}{|l|l|l|}
\cline { 2 - 3 } 21 & NEGATIVO & POSITIVO \\
\hline 22 & NEGATIVO & NEGATIVO \\
\hline 23 & POSITIVO & POSITIVO \\
\hline 25 & NEGATIVO & NEGATIVO \\
\hline 26 & NEGATIVO & POSITIVO \\
\hline 29 & NEGATIVO & POSITIVO \\
\hline 31 & NEGATIVO & NEGATIVO \\
\hline 32 & POSITIVO & POSITIVO \\
\hline 33 & POSITIVO & POSITIVO \\
\hline 34 & NEGATIVO & NEGATIVO \\
\hline 35 & POSITIVO & POSITIVO \\
\hline 36 & NEGATIVO & NEGATIVO \\
\hline 38 & POSITIVO & POSITIVO \\
\hline 39 & POSITIVO & POSITIVO \\
\hline 40 & POSITIVO & POSITIVO \\
\hline 41 & NEGATIVO & NEGATIVO \\
\hline 42 & NEGATIVO & POSITIVO \\
\hline 44 & NEGATIVO & NEGATIVO \\
\hline 45 & NEGATIVO & NEGATIVO \\
\hline 46 & NEGATIVO & NEGATIVO \\
\hline 47 & NEGATIVO & POSITIVO \\
\hline 48 & NEGATIVO & POSITIVO \\
\hline 49 & NEGATIVO & POSITIVO \\
\hline 50 & NEGATIVO & NEGATIVO \\
\hline 51 & POSITIVO & POSITIVO \\
\hline 52 & NEGATIVO & NEGATIVO \\
\hline 53 & NEGATIVO & POSITIVO \\
\hline 54 & NEGATIVO & NEGATIVO \\
\hline 55 & POSITIVO & POSITIVO \\
\hline 56 & NEGATIVO & NEGATIVO \\
\hline
\end{tabular}

Fonte: dos autores, 2016

LEGENDA: 
NEGATIVO- Não se obteve crescimento de micro-organismos na amostra analisada. POSITIVO- Se obteve crescimento de micro-organismos na amostra analisada.

Para o $\mathrm{N}$ amostras de 56 amostras, foi observado positividade no crescimento na metodologia de MAKI em 17 das 56 amostras e 39 resultados negativos, em contrapartida foram obtidos 30 resultados postivos e 26 negativos na metodologia de sonicação, correspondendo a $53,5 \%$ das amostras analisadas, contra $30 \%$ das positivas na metodologia de Maki, Correspondendo a um numero de falso negativos de $23,5 \%$.

Em relação aos micro-organismo isolados, foram separados de acordo com a icidencia de isolamento, em referência as duas metodologias, como demostrados nos gráficos 1 e 2 abaixo.

\section{Gráfico 1- Cepas Identificadas Metodologia de Sonicação}

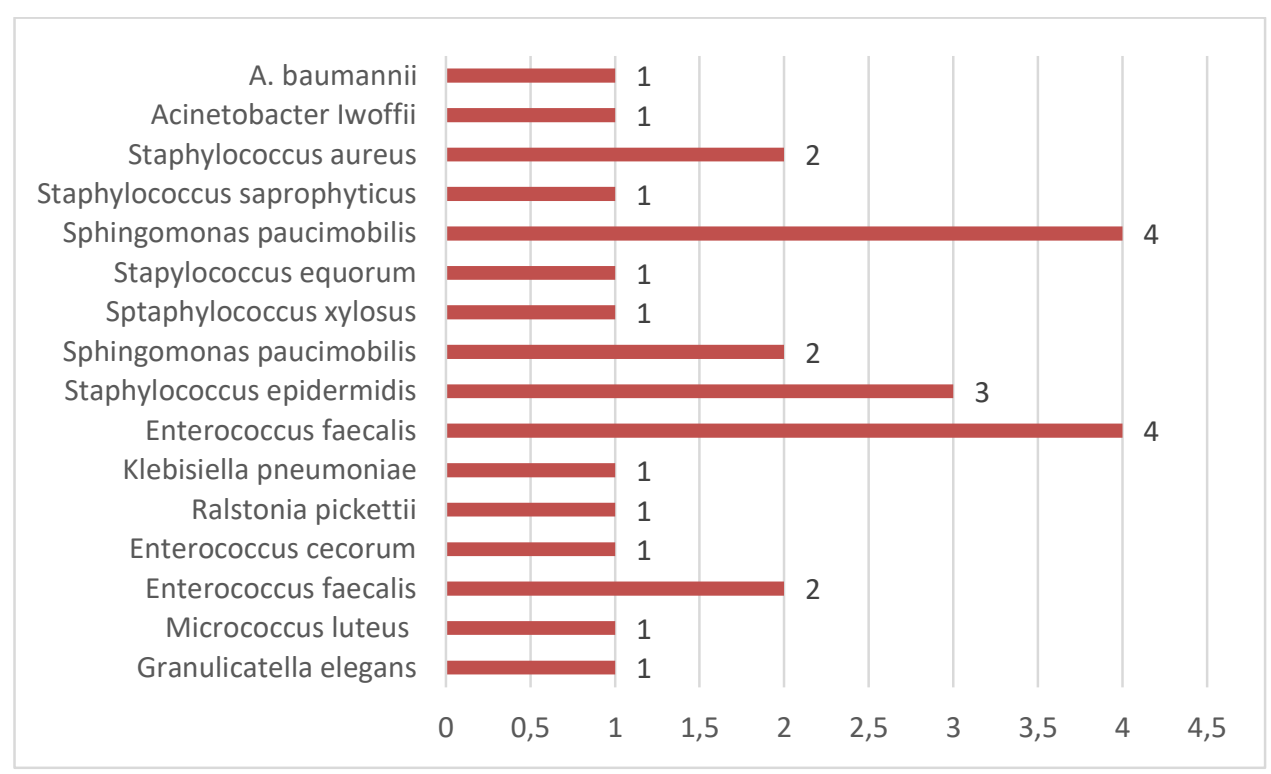

Fonte: dos autores, 2017

\section{Gráfico 2- Cepas Identificadas Metodologia de MAKI}




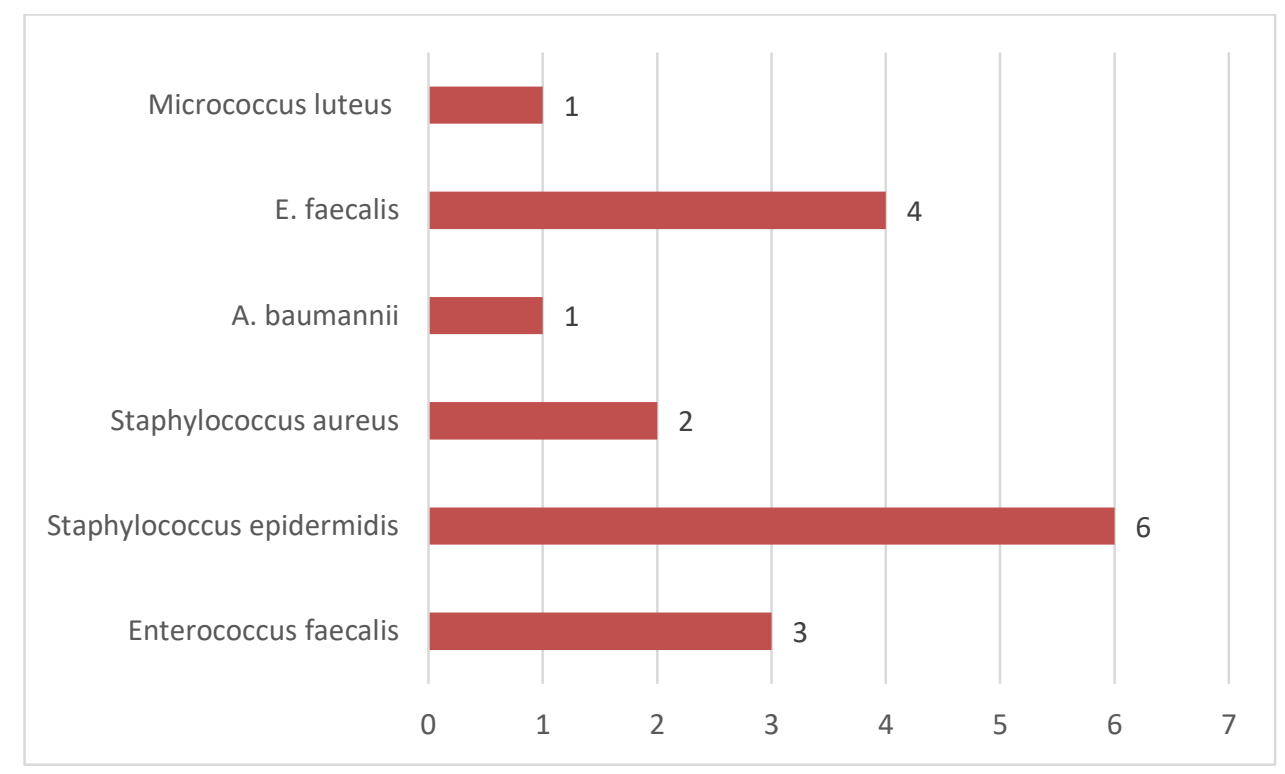

Fonte: dos autores, 2017

Para ser avaliado o perfil de resistência a antimicrobianos foi realizado a partir da cepa de origem a metodologia do VITEK®, onde são pré selecionados os antibióticos para cada cepa.

\section{DISCUSSÃO}

A retirada e a posterior cultura do cateter vascular foram empregadas durante muito tempo como padrão-ouro para o diagnóstico de infecção relacionada a cateter, especialmente nos casos de cateter de pouca permanência. A principal limitação da cultura da ponta do cateter é que na realização da técnica desenvolvida por Maki. Esta metodologia consiste na rolagem do cateter retirado em meio de cultura com o auxílio de uma pinça, e se objetiva o isolamento de patógenos presentes no exterior do cateter, já aqueles que possam estar aderidos em forma de biofilme no lúmen do cateter podem muitas vezes chegarem a não são identificados, ocasionado resultados falsonegativos (MAKI, 1994; MENOITA et al., 2012).

Devido à simplicidade e baixo custo, a sonicação de dispositivos biomédicos, vem se tornando o método mais promissor entre as técnicas mais recentes para o diagnóstico de infecção associados a implantes, o qual possui uma sensibilidade alta (80\%) em comparação com métodos anteriores. O banho ultrassônico pode ser definido por uma energia ultrassônica que é aplicada diretamente à superfície do 
implante, conseguindo desalojar e recuperar bactérias aderidas, as quais se encontram em biofilmes sobre implantes (TRAMPUZ et al. 2006, UMETA, 2015).

Bakker et al. (1998) confirmaram cerca de 46 casos (26\%), onde possuem três tipos de micro-organismos, onde o Staphylococcus epidermidis causou infecção em 40 pessoas com casos de infecções (43\%) e Staphylococcus aureus, Enterococcus spp. em (7\%) dos casos.

Kim et al. (2004) confirmaram dez casos de infecções, onde quatro por Staphylococcus sp. e um por Pseudomonas aeruginosa. É possível observar que outro micro-organismo que é frequentemente isolado nas infecções sanguíneas foram Staphylococcus epidermidis, Pseudomonas aeruginosas que são encontrados em $9,5 \%$ dos casos.

O estudo divulgado por Castanho et al. (2010) mostrou que em 28 casos de infecções (49\%), e que $100 \%$ dos patógenos isolados eram gram negativos como: Stenotrophomonas maltophilia responsável por quatro dos casos de infecção (25\%) as outras bactérias que foram isoladas em relação ao número de casos, são: Pseudomonas fluorescens (02), Pseudomonas aeruginosas (01), Acinetobacter baumannii (02), Acinetobacter hvoffi (01), Klebsiella pneumoniae (02), Klebsiella oxytoca (01), Enterobacter cloacae (02), Serratia marcescens (01).

Através da análise dos dados da Anvisa no ano de 2014, foi possível identificar: ocorrências de 15.434 infecções de cateter venoso central em UTI Adulto, destes, 17\% são Staphylococcus coagulase negativa, totalizando 3.911 infecções, e em 3.333 casos o Staphylococcus aureus é o micro-organismo que 12 mais predomina, foram ainda identificados: Klebsiella pneumoniae (3.266), Acinetobacter spp. (2.960), Pseudomonas aeruginosa (2.480), Escherichia coli (1.706) e Candida sp.; com 1.516 casos (BRASIL, 2014).

Elliott et al. (1997) relataram que os microrganismos que colonizam o cateter venoso central incluem o Staphylococcus coagulase-negativa, Staphylococcus aureus, Pseudomonas aeruginosa, Klebsiella pneumoniae, Enterococcus faecalis e Candida albicans. 
Raad (1998) relatou que os microrganismos emergentes das espécies de Micrococcus, Acromobacter, micobactérias tais como Mycobacterium fortuitum, $M$. chelonei e fungos tais como Malassezia furfur, espécies de Rhodotorula, Fusarium, Trichosporon e Hansenula anomola têm também causado infecções da corrente sanguínea relacionada aos cateteres.

Sherertz (2000) relataram que Staphylococcus aureus, Staphylococcus epidermidis e Candida albicans são desproporcionalmente causas comuns de infecção relacionada ao cateter. O Staphylococcus epidermidis produz slime que ajuda sua sobrevivência sobre corpos estranhos e Staphylococcus aureus produz significante número de fatores de virulência, incluindo proteínas que interagem com o sistema de coagulação e com a matriz extracelular, a qual faz isso unicamente adaptada para sobreviver dentro do vaso sanguíneo. Candida albicans pode crescer bem em fluído de hiperalimentação (o fluído usado na nutrição parenteral) e também adere bem às proteínas de matriz extracelular, tais como fibrinogênio e fibronectina.

Donlan (2001) relatou que os biofilmes sobre cateteres podem ser compostos de bactérias Gram-positivas, Gram-negativas e fungos. As bactérias comumente isoladas do cateter incluem os Gram-positivos: Enterococcus faecalis, Staphylococcus aureus, Staphylococcus epidermidis e Streptococcus viridans. Os Gram-negativos Escherichia coli, Klebsiella pneumoniae, Proteus mirabilis e Pseudomonas aeruginosa. Estes organismos podem originar-se da pele de 21 pacientes ou do pessoal da saúde, da água potável na qual ficam expostos os conectores, ou de outras fontes no meio ambiente.

Os biofilmes podem ser compostos de espécies únicas ou múltiplas espécies de microrganismos, depende do cateter o tempo de uso no paciente. Uma vez o cateter colonizado por microrganismos, eles são difíceis de tratar e tornam-se altamente resistentes aos agentes antimicrobianos sistêmicos porque estão agrupados em uma camada de biofilme de sua própria produção ou do hospedeiro.

Dos resultados encontrados nas análises microbiológicas das amostras de cateter venoso central ao se comparar a metodologia de Maki e Sonicação observouse que a metodologia de Sonicação apresenta melhorias na identificação de micro- 
organismos, obtendo resultados positivos em mais de $53 \%$ dos casos, contra $30 \%$ do Padrão ouro, obtendo-se assim um resultado de falsos negativos mais de $23 \%$.

$\mathrm{Na}$ pesquisa realizada por Lima, et. al.(2007), a metodologia de sonicação também apresentou resultados mais satisfatórios em relação ao MAKI, devido a capacidade do banho ultra sônico de promover o descolocamento dos microorganismos do lumen do cateter e aqueles presentes em biofilmes, melhorando assim o diagnóstico e a qualidade de vida do paciente submetido a retirada do cateter por ter uma suspeita de infecção. Observa-se que é importante salientar que o método de sonicaçao é importante quando tratasse de agentes causadores de biofilmes, onde, nestes casos, um resultado falso negativo leva ao retardo do tratamento especifico.

Stroti, 2006, retrata que os micro-organismo mais comumente isolados e causadores de infecção em cateter são os do gênero Staphylococcus spp. o que corroba aos dados encontrados no presente estudo onde 8 dos micro-organismo isolados são pertencentes ao gênero. Um fato importente ainda sobre a adesão destes micro-organismos e o motivo de seu grande percentual de isolamento está nas proteínas liberadas pelo sistema imune do paciente na tentativa de evitar a infecção, como por exemplo a trombina, que é rica em fibronectina e fibrina, duas substancias em que subespécies de Staphylococcus e alguns fungos se aderem fortemente.

Os Staphylococcus são os micro-organismos mais encontrados na pele, sua presença em processos infecciosos pode-se ser originada a má higenização na hora da inserção do cateter ou na troca de curativo, tanto pelos profissionais de saúde como pelo próprio paciente e acompanhante. O que pode levar a um uma disseminação hematogenica no sitio de inserção do cateter até um local distante, podendo ocasionar até uma sepse neste paciente (CRUMP e COLLIGNON, 2000).

A aderência do microrganismo a um material específico depende das propriedades físicas do cateter, como a qualidade da superfície. Depois que o microrganismo coloniza o cateter, prolifera formando biofilme e começa migrar. Os microrganismos podem disseminar-se da ponta do cateter para a corrente sanguínea por meio das infusões, manipulações e movimentos fisiológicos do cateter e, desta forma, causar infecção sistêmica, conforme relatado por Raad (1998). 
O estudo realizado por Sherertz et al. (1997), comparou três métodos de cultura de ponta de cateter, entre eles o método de MAKI e a Sonicação, além da lavagem do lumen do cateter (Flush), observando que o método de emprego da Sonicacao foi mais sensível em $20 \%$ em relação aos outros, o que corroba nosso estudo onde encontramos o valor de $23,5 \%$ de divergência entre as duas metodologias. Tendo a sensibilidade de $80 \%$ para sonicação e Maki de $60 \%$.

No estudo de Stroti, 2006, demostrou que existe correlação linear entre os dois métodos de cultura de cateter, onde irá depender do tempo de inserção, início da sintomatologia e retirada e processamento da amostra, sendo que quanto mais rápido ocorrer o processamento da amostra, em nosso estudo foi utilizado 4 horas, a partir da sonicação, mais sensível se torna a metodologia. Em relação aos microorganismos isolados $50 \%$ foram identificados Staphylococcus aureus, Stenotrophomonas maltophilia (25\%) e Citrobacter freundii (25\%), dados concordantes com Bullard e Dunn (1996) e não concordantes com Bouza et al. (2002) que relataram que os micro-organismos mais isolados de infecção relacionada ao cateter são Staphylococcus coagulase-negativa (30 a 40\%), Staphylococcus aureus (5 a 10\%). Em nosso estudo os dados corrobam, pois o maior numero de microorganismos identificados foram os Staphylococcus coagulase negativa (38\%).

No estudo de Polderman e Girbes (2002) e Fätkenheuer et al. (2003) é retratado que os Staphylococcus coagulase-negativa são os microrganismos mais freqüentemente isolados em hemoculturas. $O$ presente estudo, em relação aos microrganismos isolados de cateteres tanto por método de MAKlquanto por método Sonicação eram Gram-positivos e Gram-negativos. Dados consistentes com Donlan (2001), Donlan e Costertan (2002) e Pascual (2002) onde relatam que as espécies de microrganismos mais comumente isolados de biofilmes de cateteres são $\mathrm{S}$. epidermidis, S. aureus, K. pneumoniae e Enterococcus faecalis.

Para as 56 amostras analisadas, foi observado positividade no crescimento na metodologia de MAKI em 17 das 56 amostras e 39 resultados negativos, em contrapartida foram obtidos 30 resultados positivos e 26 negativos na metodologia de sonicação, correspondendo a $53,5 \%$ das amostras analisadas, contra $30 \%$ das 
positivas na metodologia de Maki, Correspondendo a um numero de falso negativos de $23,5 \%$.

Quanto ao perfil de sensibilidade dos microrganismos isolados de ponta de cateter e sangue, observou-se que $100 \%$ dos S. aureus eram meticilina resistentes. Os dados são consistentes com a literatura de Pfaller et al. (1998), os quais relataram que a resistência a oxacilina entre os estafilococos é muito mais observada em patógenos isolados de hospital. No entanto, as taxas são mais altas do que as notificadas pelo Programa de vigilância antimicrobiana SENTRY, nos Estados Unidos $(26,2 \%)$ e no Canadá $(2,7 \%)$ de Staphylococcus aureus meticilina resistentes.

Friedman et al. (2002), em um estudo retrospectivo, mostraram que em um período de 10 anos a sepse devido à Stenotrophomonas maltophilia ocorreu em 44 pacientes. A maioria dos pacientes tinha cateter venoso central, o que enfatiza a importância dos cateteres venosos centrais como fator de risco para bacteriemia.

A dificuldade de produção de novos antibióticos vem crescendo a cada dia, devido à grande gama de infecções por bactérias resistentes e o uso indiscriminado de antibióticos, sendo ainda um número limitado de drogas que produzem efeito em bactérias presentes em biofilmes, devido muitas vezes a diversidade antimicrobiana encontrada nos biofilmes, são utilizadas altas doses de antibióticos, no intuito de se conseguir transpassar o EPS, como também a combinação de drogas, para o tratamento de espécies diferentes (SALDANHA, 2013).

No entanto, a combinação destas drogas pode induzir a resistência bacteriana, quando mesmo em altas doses não obtém o efeito desejado. Podendo aumentar o tempo de infecção, tratamento e diminuindo a qualidade de vida do paciente devido a toxicidade destas drogas em seu organismo (SALDANHA, 2013; BRASIL, 2014c). No ano de 2012, avaliando os dados de resistência dos cocos Gram positivos, observase que a bactérias Staphylococcus coagulase-negativo (SCoN), dos 3.788 casos notificados, $75,1 \%$ eram resistentes à oxacilina, seguidos do $\mathrm{S}$. aureus resistentes à oxacilina correspondendo a 52,9\% (1.657) dos dados notificados e 19,1\% dos isolados de Enterococcus spp. tinham resistência à vancomicina (BRASIL, 2014).

Entre os Gram negativos, foram avaliados os grupos das enterobactérias e bacilos Gram negativos não fermentadores, onde o grupo das enterobactérias apresentou resistência a carbapenens, e às cefalosporinas de terceira e quarta 
geração, ao avaliar os percentuais de resistência observou-se que dos 2.363 casos notificados de infecção por Klebisiella pneumoniae, 25,3\%, eram resistentes às cefalosporinas de amplo espectro e carbapenens, e 35,6\% dos isolados de Pseudomonas aeruginosa são resistentes a carbapenens (BRASIL, 2014).

O programa SENTRY (Antimicrobial Surveillance Program) que é um programa mundial e longitudinal de Vigilância de Resistência Bacteriana, que avalia os patógenos isolados em laboratórios de microbiologia, bem como seu perfil de resistência a antimicrobianos utilizando para tal, testes de referência em antimicrobianos como por exemplo microdiluição em caldo, relatou que entre os anos de 2005 e 2008, a bactéria Staphylococcus aureus é tida como o agente etiológico de maior prevalência nos casos isolados, este micro-organismo é de grande relevância em estudos, pois é um patógeno amplamente disseminado, faz parte da microbiota natural de humanos e animais além de possuir formas resistentes que podem ser propagadas e causar infecções graves e levar o paciente ao óbito, como é o caso de MRSA (Staphylococcus aureus resistente a meticilina) e VRSA (Staphylococcus aureus resistente à vancomicina). As bactéria Klebisiella pneumoniae, também citada, é um bacilo Gram negativos e tem relevância em estudos devido a ser um dos patógenos mais isolados em amostras laboratoriais e serem responsáveis pela produção do plasmídeo de resistência (KPC), sendo estes três os agentes mais isolados de infecções de corrente sanguínea (SADER et al., 2001; SIEVERT, 2013; PASCHOAL, 2010, BRASIL, 2014c).

O controle da resistência bacteriana é complexo e exige a ação de um conjunto de setores ao mesmo tempo, as atividades que tem maior eficácia envolvem o controle da disseminação de bactérias resistentes tanto no hospital como na comunidade e o uso dos antibióticos de maneira racional. Para isso é necessário entender como as bactérias resistentes se disseminam para que medidas controle mais adequadas para determinado local possam ser utilizadas. Por outro lado, para que os antibióticos sejam empregados adequadamente, especialmente no tratamento empírico, é necessário o conhecimento dos mecanismos de resistência bacteriana envolvidos, e como estes se relacionam ao se deparar com diferentes classes de antibióticos, ou mesmo por diferentes drogas de uma mesma classe, é valido ressaltar a importância de mecanismos de controle de infecções hospitalares e programas de 
conscientização, tanto para a população quanto para os profissionais de saúde (PASCHOAL, 2010).

Friedman et al. (2002) relatam que a terapia com carbapenem favorece a seleção de Stenotrophomonas maltophilia, predispondo a colonização e superinfecção com este microrganismo. Tradicionalmente, esse microrganismo é resistente a todos os betalactâmicos, aminoglicosídeos e carbapenens. No presente estudo, observou-se resistência aos beta-lactâmicos, aminoglicosídeos e carbapenem.

\section{CONCLUSÃO}

Conclui-se com este estudo que a avaliação microbiológica permitiu avaliar e detectar micro-organismos que colonização não só o lumen mais também a exterior do caterer além de se supor que os resultados positivos na metodologia de sonicação em comparação com o MAKI é devido a presença de biofilme.

O diagnóstico de confiabilidade de ambos os métodos divergentes, sendo a sonicação mais sensível em comparação ao MAKI. O perfil de resistência apresentado pelos micro-organismos demostrou-se parecido. A cultura de ponta de cateter venoso central usando técnica semi-quantitativa pode ser usada como um indicador de bacteriemia relacionada os cateteres de venoso central.

É necessário o treinamento com a equipe no intuito de se conscientizar a importância da biossegurança e boas práticas, em vista da saúde de pacientes no ambiente hospitalar, além da concientizacao e treinamento continuo do corpo de trabalho laboratorial em relação a contaminação cruzada. 


\section{REFERENCIAS BIBLIOGRÁFICAS}

ATELA, I.; COLL, P.; RELLO, J.; QUINTANA, E.; BARRIO, J.; MARCH, F.; SANCHEZ, F.; BARRAQUER, P.; BALLÚS, J.; COTURA, A.; PRATS, G. Serial surveillance cultures of skin and catheter hub specimes from critically ill patients with central venous catheter: molecular epidemiology of infection and implications for clinical management and research. J. Clin. Microbiol., v. 35, n. 2, p. 1784-1790, 1997.

ALBUQUERQUE, M. P. Cirurgia dos cateteres de longa permanência (CLP) nos centros de transplante de medula óssea. Medicina, Ribeirão Preto. v. 38, n. 2, p.125142, abr./jun.2015

BAKKER, J. et al. Infectious Complications of Radiologically Inserted Hickman Catheters in Patients whit Hematologic Disorders. Cardiovascular and Interventional Radiology, New York, v. 21, n. 2, p.116-121, mar./apr.1998

BRASIL, Ministério da Saúde. Agência Nacional de Vigilância Sanitária (ANVISA) Rede Nacional de Monitoramento da Resistência Microbiana em Serviços da SaúdeRede RM: Resistência Microbiana em IPCSL relacionada a CVC em UTI (2012). Boletim Informativo - Segurança do Paciente e Qualidade em Serviços da Saúde, (p.1-26). Ano IV, no 7. Brasília, mar. /2014.

BOUZA, E.; BURILLO, A.; MUNOZ, P. Catheter-related infections: diagnosis and intravascular treatment. Clin. Microbiol. Infect., v. 8, p. 265-274, 2002.

BRASIL, Agência Nacional de Vigilância Sanitária. Indicadores Nacionais de Infecções Relacionadas à Assistência à Saúde. Unidade de Investigação e Prevenção das Infecções e dos Eventos Adversos. Brasília, p. 1-17 set. 2010

BULLARD, K. M.; DUNN, D. L. Diagnosis and treatment of bacteremia and intravascular catheter infections. Am. J. Surg., v. 172, supp. 6A, p. 13-19, 1996. 
COLLIGNON, P. J. Australian study on intravascular catheter associated sepsis. intravascular catheter associated sepsis: a common problem. Med. J. Aust., v. 161, n. 2, p. 374-378, 1994.

CRUMP, J. A.; COLLIGNON, P. J. Intravascular catheter-associated infections. Eur. J. Clin. Microbiol. Infect. Dis., v. 19, n. 1, p. 1-8, 2000

CAUMO, K.; DUARTE M.; CARGNIN S.T.; RIBEIRO, V.B.; TASCA, T.; MACEDO, A.J.; Resistência bacteriana no meio ambiente e implicações na clínica hospitalar, Revista Liberato, Novo Hamburgo, v.11. n. 16, p. 89-96, jul. /dez. 2010.

COSTERNON, el al. "The Bacterial Glycocalix in Nature and Disease". Annu Rev. Microbiol., v.35, p.299-304, jan. 1981.

CAIXETA, D.S. Sanificantes químicos no controle de biofilmes formados por duas espécies de Pseudomonas em superfície de aço inoxidável. Dissertação (Mestrado em Microbiologia Agrícola) - Universidade Federal de Lavras, Lavras, 2008.

CRUMP, J. A.; COLLIGNON, P. J. Intravascular catheter-associated infections. Eur. J. Clin. Microbiol. Infect. Dis., v. 19, p. 1-8, 2000.

COUTO, R. C.; PEDROSA, T. M. G.; NOGUEIRA, J. M. Infecção hospitalar e outras complicações não-infecciosas da doença: Epidemiologia, controle e tratamento.ed. Rio de Janeiro: Guanabara Koogan, 2009.

CASTANHO, L. C. et al. Motivo de retirada de cateter de Hickman em pacientes submetidos ao transplante de células-tronco hematopoiéticas. Acta Paulista de Enfermagem, São Paulo, v. 24, n. 2; p. 244-248. Jan.2011.

CDC - Centers for Disease Control and Prevention. Reduction in Central LineAssociated Bloodstream Infections Among Patients in Intensive Care Units, Pennsylvania, April 2001 - March 2005. Morbitidy and Mortality Weekly Report, Atlanta, v.54, n.40, p. 1013-1016, mar. 2011. 
DANESE, P. N. Antibiofilm approaches: prevention of catheter colonization. Chem. Biol., v. 9, p. 873-880, 2002.

DRUSKIN, M. S.; SIEGEL, P. D. Bacterial contamination of indwelling intravenous polyethylene catheters. JAMA, v. 185, n. 2, p. 966-968, 1963.

DONLAN, R.M.; COSTERTON, J.W. Biofilms: survival mechanisms of clinically relevant microorganisms. Clinical Microbiology Reviews, Washington, v. 15, p.167193, Abr. 2002.

DONLAN, R. M.; et al. Protocol for detection of biofilms on needleless connectors attached to central venous catheters. Jornaul Clinical Microbiology. Washington, $v$. 39, p. 750-753, fev. 2001.

DIENER, J. R. C.; COUTINHO, M. S. S. A.; ZOCCOLI, C. M. Infecções relacionadas ao cateter venoso central em terapia intensiva. Rev Assoc Med Bras. Rio de Janeiro, v. 42, n. 4, p. 205-14. Mar, 2006.

ELLIOTT, T.S.J.; TEBBS, S. E.; WILSON, I. C.; BONSER, R. S.; GRAHAM, T. R.; BURKE, L. P.; FAROQUI, M. H. Novel approach to investigate a source of microbial contamination of central venous catheters. Eur. J. Clin. Microbiol. Infect. Dis., v. 16, p. 210-213, 1997.

OLIVEIRA A.C.; DAMASCENO Q.S.; RIBEIRO, S.M.C.P. Infecções relacionadas à assistência em saúde: desafios para a prevenção e controle. Revista mineira de Enfermagem, Minas Gerais, v.13, n.3, p. 445-450, jul. /set. 2009. 
FÄTKENHEUER, G.; et al. Central venous catheter (cvc)-related infections in neutropenic patients. Ann. Hematol., v. 82, Suppl 2, p. S149-S157, 2003.

HENRIQUES, A.; VASCONCELOS, C.; CERCA, N. A importância dos biofilmes nas infecções nosocomiais- o estado da arte. Artigo de Revisão, Arquivos de medicina, Porto, Portugal, v. 27, n. 1, p. 27-36, fev. 2013.

HASSAL, J. E.; ROUNTREE, P. M. Staphylococcal septicemia. Lancet, v. 1, n. 2, p. 213-217, 1959.

HOIBY, N. et al. The clinical impact of bacterial biofilms. International Journal of Oral Sciences, India, v. 3, n. 3, p. 55-65, Abril, 2011.

LÓPEZ, D.; VLAMAKIS, H.; KOLTER, R. Biofilms. Cold Spring Harbor Perspectives in Biology, v. 2, n. 2, p. 1-11, fev. 2010.

LEWIS, K. Persister cells: molecular mechanisms related to antibiotic tolerance. Handbook of Experimental Pharmacology. Journal bacteriology, New York, v. 211, p. 121-133, Jan. /Dez. 2012.

MENOITA, E. et al. Biofilmes: conhecer a entidade. Journal of aging and innovation, Lisboa, v.1, n. 3, p. 23-32, abr. 2012.

MORAES, M.N., et al. Mecanismos de adesão bacteriana aos biomateriais, Revista de Medicina de Minas Gerais, v. 23, n. 3, p. 99-10, Belo Horizonte, jan. 2013.

MERMEL, L. A.; ALLON, M.; BOUZA, E.; CRAVEN, D. E.; FLYNN, P.; O'GRADY, N. P. Clinical practice guidelines for the diagnosis and management of intravascular catheter-related infection: Update by the Infectious Diseases Society of America. Clin Infect Dis. Alabama, v. 49, n.1, p. 1-45, jul. 2009.

MAH, T.F. Biofilm-specific antibiotic resistance. Future Microbiology, Inglaterra, v. 9, n. 24, p. 1061-1072, set. 2012. 
MAKI, D. G.; CRINCH, J. Line sepsis in the ICU: Prevention, diagnosis and management. Semin. Respir. Crit. Care. Med., v. 24, n. 2, p. 23-26, 2003.

MESIANO, E. R. A. B.; HAMANN, E. M. Infecções da corrente sanguínea em pacientes em uso de cateter venoso central em unidades de terapia intensiva. Revista Latino Americana de Enfermagem, Ribeirão Preto, v.15, n.3, p. 453- 459, 2007

MARTINS, L.M.M., LIMA, A. R. Cuidados com o paciente que utiliza do cateter de Hickman- Broviac- um estudo de caso. Revista da Escola de enfermagem da USP, v. 32, n. 3, p.187-191, São Paulo, out.1998.

MAKI, D. G.; GOLDMAN, D. A.; RHAME, F. S. Infection control in intravenous therapy. Ann. Intern. Med., v. 79, n. 6, p. 867-87, 1973.

MONCRIEF, J. A. Femoral catheters. Ann. Surg., v. 147, p. 166-172, Mar. 1958.

INDAR, $R$. The dangers of indwelling polyethylene cannulae in deep veins. Lancet, $v$. 1, p. 284-286, jan. 1959.

NEUHOF, H.; SELEY, G. P. Acute suppurative phlebitis complicted by septicemia. Surgery, v. 21, p. 831-842, dez. 1947.

NEVES JUNIOR, M.A; et al. Infecções em cateteres venosos centrais de longa Permanência: revisão da literatura. Jornal Vascular Brasileiro. São Paulo, v.9, n.1 p.46-50, abr. 2010.

$\mathrm{NIH}$ : National Institutes of Health [Internet]. 2002. Available from: http://grants.nih. gov/grants/guide/pa-files/PA-03-047.html.

NEIDELL, M.J. et al. Costs of healthcare and community-associated infections with antimicrobial-resistant versus antimicrobial-susceptible organisms. Clinical Infectious Disease, Chicago, v. 55, p. 807-815, Set. 2012. 
OLIVEIRA A.C.; DAMASCENO Q.S.; RIBEIRO, S.M.C.P. Infecções relacionadas à assistência em saúde: desafios para a prevenção e controle. Revista mineira de Enfermagem, Minas Gerais, v.13, n.3, p. 445-450, jul. /set. 2009.

PASCUAL, A. Pathogenesis of catheter-related infections: lessons for new designs. Clin. Microbiol. Infect., v. 8, p-256-264, 2002.

PINHEIRO S.; Formação de biofilmes: um breve ensaio. Intravenous, publicação especializada em terapia intravenosa, ano VI, n 16.p.2-3. Jan/maio 2006.

POLDERMAN, K. H.; GIRBES, A. R. J. central venous catheter use part 2: infectious complications. Intensive. Care. Med., v. 28, p. 18-28, 2002.

RUTHERFORD, S.T.; BASSLER, B.L. Bacterial quorum sensing: its role in virulence and possibilities for its control. Cold Spring Harbor Perspectives in Medicine, New York, v. 2, n. 2, p. 1-26, Nov. 2012

RAAD, I. Intravascular-catheter-related infections. Lancet, v. 351, p. 893-898, 1998.

RAAD, I.; BODEY, G. P. Infectious complications of indwelling vascular catheters. Clinic. Infect. Dis., v. 15, n. 1, p. 197-210, 1992.

RIMONDINI, L.; FINI, M.; GIARDINO, R. The microbial infection of biomaterials: a challenge for clinicians and researchers. a short review. J. Appl. Biomater. \& Biomech, v. 3, n. 1 p. 1-10, jun. 2005.

SCHIESARI JUNIOR, A. et al. Infecções por bactérias formadoras de biofilme: breve revisão. Revista Brasileira de Medicina Interna, v.2 n. 1 p. 37-47, Cantanduva -São Paulo, 2015. 
SILVEIRA, R. C. C. P.; GALVÃO, C. M. O cuidado de enfermagem e o cateter de Hickman: a busca de evidências. Acta paulista Enfermagem, São Paulo, v.18, n. 3, 2005.

SALDANHA, J.T.; Emprego de nanopartículas em estratégias de prevenção e tratamento de infecções relacionadas à formação de biofilmes bacterianos. Instituto Federal de Educação, Ciência e Tecnologia do Rio de Janeiro, Rio de janeiro, Set. 2013.

STOODLEY, P.et al. Biofilms as complex differentiated communities. Annual Review of Microbiology, Palo Alto, v. 56, n. 3, p. 187-209, Jan. 2002.

SHERERTZ, R. J. Microbial interactions with catheter material. Nutrition, v. 13, (Suppl) p. 5S-9S, 1997.

STORTI, A. COLONIZAÇÃO DE CATETERES VENOSOS CENTRAIS POR BIOFILME MICROBIANO, Programa de PósGraduação da Faculdade de Ciências Farmacêuticas, câmpus de Araraquara - UNESP, São Paulo, 2006.

STEWART, P.S. Mechanisms of antibiotic resistance in bacterial biofilms. International Journal of Medical Microbiology, Inglaterra, v. 292, n. 2, p. 107-113, jul. 2002.

SHERERTZ, R. J. Pathogenesis of vascular catheter infections. In: WALDOVOGEL, F. A.; BISNO, A. L. (Eds). Infections associated with indwelling medical devices. Washington: ASM Press; 2000, p. 111-125.

TRENTI D.S.; GIORDANI, R.B.; MACEDO A.J.; Biofilmes bacterianos patogênicos: aspectos gerais, importância clínica e estratégias de combate. Programa de Pósgraduação de Ciências Farmacêuticas da Universidade Federal do Rio Grande do Sul, Porto Alegre, v. 12, n. 2, p.24, set, 2013. 
XAVIER, J.B., et al., Monitorização e modelação da estrutura de biofilme. Boletim de Biotecnologia, São Paulo, 2005

WEBER, I. C.; NOAL, C. B.; WINCKLER NETO, C. H. D. P.; SANTOS, R. C. V. Prevalência e perfil de resistência de microorganismos isolados de uma unidade de tratamento intensivo de um hospital da região central do Rio Grande do Sul. Prat Hosp. Rio Grande do Sul, v. 66, n. 3, p. 57-62, nov. 2009. 